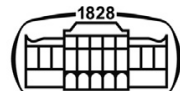

AKADÉMIAI KIADÓ

UNIVERSITY of DEBRECEN

\section{International Review of Applied Sciences and Engineering}

$12(2021) 3,278-284$

Dol:

$10.1556 / 1848.2021 .00271$

(c) 2021 The Author(s)

\section{ORIGINAL RESEARCH} PAPER

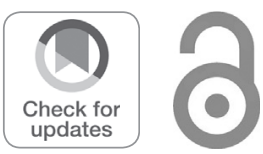

\title{
Investigation on strength properties of polymer modified concrete using glycoluril
}

\author{
SKM. Pothinathan ${ }^{1 *} \odot$, M. Muthukannan ${ }^{1} \odot$, N. Selvapalam ${ }^{2}$ and \\ S. Christopher Gnanaraj ${ }^{1}$ \\ ${ }^{1}$ Department of Civil Engineering, Kalasalingam Academy of Research and Education, Krishnankoil, \\ 626126, Tamilnadu, India \\ ${ }^{2}$ Department of Chemistry, Kalasalingam Academy of Research and Education, Krishnankoil, \\ 626126, Tamilnadu, India
}

Received: March 9, 2021 • Accepted: April 21, 2021

Published online: May 26, 2021

\begin{abstract}
In this study, an endeavor is made to discuss mainly the mechanism, use, and application of polymer modified concrete which is increasing in general fame due to its simplicity, ease of handling, proficiency, and agreeable outcomes. This work explores the impact of adding a new polymer named glycoluril on the mechanical property through the estimation of compression, tension, and flexural strength. Physical properties such as density, sorptivity, and acid resistance were studied to establish the durability of concrete. This examination additionally ponders the impact of polymer in concrete and polymer dosage. Series of concrete mix with $0 \%, 1 \%, 2 \%, 3 \%$, and $4 \%$ glycoluril by the mass of binder were prepared, cured, and tested in 7 days and 28 days. Results indicate that there is no adjustment in the workability aspect, however, the improvement of strength factor in compression, tension, and flexure is recorded when compared with the conventional concrete. The experimental results show that by increasing the proportion of glycoluril, the strength of concrete increased up to $3 \%$ in addition. In the meantime, the $3 \%$ addition provided a higher outcome than the other blend. Further expanding the polymer content marginally decreased the strength. The outcome affirms that the utilization of new polymer in concrete will increase the desired property.
\end{abstract}

\section{KEYWORDS}

glycoluril, polymer modified concrete, compression, tension

\section{INTRODUCTION}

Cement concrete has acceptable resistant properties in all environmental conditions. But normal cement composites are not recommended for deterioration processes like mechanical, chemical electrochemical and some extreme weather conditions [1], and also the heat of hydration during the hardening process leads to shrinkage, inner pores which permit the reduction of strength and durability. In this situation, some additives are used to improve the desirable properties of concrete which are suited for the environmental condition. Polymers are the well-matched additives in special conditions where mechanical strength, water tightness, abrasion resistance, freeze and thaw, durability, corrosion resistance, and repairing old concrete structures are needed [2]. Polymers are also used to make self healing concrete [3]. Using polymers may lead to a little higher cost compared to ordinary concrete. But the result produced in the practical situation may turn the polymer concrete into special concrete. Polymers in the cement concrete were evenly distributed inside the concrete pores and improved the density. This improved density will lead to resistance to moisture penetration, corrosion of reinforcement, wear, and impact resistance. Because of this impermeability, durability and mechanical property of the concrete also increases.

Polymer concrete is classified into three types, namely polymer cement concrete, polymer concrete, and polymer-modified concrete [4]. Polymer cement concrete is widely used for 
corrosion resistance and repairing structures. In this, watersoluble polymers are used to fill the pores in cement concrete. In polymer concretes, polymer resins are used as a binder to bind the aggregates together. Due to its high cost, it is preferred for a special situation only. Next polymermodified concrete; these types of polymer concrete are ideal for conditions where the mechanical properties are of much concern. Polymers are used to modify the cement concrete to fill the pores and improve the density to achieve high strength and impermeability such as latexes, redispersible polymer powders, water-soluble polymers, liquid resins, and monomers [5].

This modification of concrete was already studied with many polymers since 1920s [5]. In recent years epoxy and latex-based polymers are widely utilized in construction practices [6-8]. Modified concrete using acrylic latex and polyurethane polyacrylate polymers were studied by Hongyan $\mathrm{Ma}$ [7]. He concludes that without heat curing the mechanical strength and elastic modulus will get reduced. Bala Muhammad [9] also noticed a reduction in strength in natural latexmodified concrete. Latex-modified concrete required admixtures like superplasticizers and antifoaming agents when the surfactants were used as stabilizers in the free radical polymerization method. Latex-modified concrete also re-emulsifies in an alkaline environment. From the works of literature, it is concluded that the latex-modified concrete requires admixtures and stabilizers to gain the required properties to perform in extreme situations. At the same time, these additions will affect the economical factor [10-12] and the process of modification will be time consuming.

Conversely, epoxy-based modified concrete plays a vital role in its high rigidness, resistance against chemical reaction, fast curing, and low permeability. Nur Farhayu Ariffin [13] used Bisphenol A-type epoxy resin as a modifying agent and observed that the alternated wet and dry curing shows the noticeable strength rise with $10 \%$ addition. L.K. Aggarwal [14] used epoxy emulsion and acrylic emulsion to modify the mortar and compared the workability and mechanical property. He noticed that the epoxy emulsion-based modified mortar performed slightly better and gave improved properties in improved workability and mechanical property and reduced water and chloride penetration. Such merits make the epoxy modifiers as generally used polymer modifying agents nowadays. However, the significant detriments of epoxy are combustibility and less thermal resistance. Some additives are recommended to overcome these detriments. But this method will affect the cost-effectiveness.

It is clearly demonstrating the requirement of new polymers to overcome negative marks of the polymers available on the market. This study aims to use a new polymer named glycoluril-formaldehyde resin as a modifying agent to prepare high-strength concrete. Formaldehyde-based additives are not a new part of the construction industry. Superplasticizers like sulfonated naphthaleneformaldehyde resins, and sulfonated melamine-formaldehyde resins are commercially available to improve workability and strength from the early 1970s [15]. There are few studies carried out by using urea-formaldehyde and phenolformaldehyde as polymer resin in mortar/concrete. Duan Hongfei [16] state that the rate of hardening of the watersoluble urea-formaldehyde based grout is slow and it takes nearly one month to stabilize. The nature of the phenolformaldehyde polymer modifiers was brittle. So, these polymer resins did not take much attention in construction industries. Glycoluril was insoluble in nature and widely used in fire-resistance materials. The $\mathrm{NH}$ group of the glycoluril may play a vital role and give good hydrogen bonding with cement. This hydrogen bonding helps to give more strength carrying capacity to the concrete. For these reasons, glycoluril was chosen to produce high strength concrete in this study.

Polymer-modified concrete is an interesting topic. It gives a solution to the construction industries where the structures are subjected to extreme environmental conditions and for repairing of concrete by means of bonding between old and new concrete [17]. Industrially available polymers are giving considerable solutions to severe conditions [18]. But they are having some demerits, like poor fireresisting property of epoxy, decreased mechanical strength and acid-resisting properties of latex [19], brittle nature of phenol-formaldehyde, and water-soluble character of ureaformaldehyde. This is the time to study the new polymer to overcome the demerits of locally available polymers. Arthur H. Gerber [20] claimed a patent contains poly-glycoluril as an accelerator for cement, no further noticeable study was conducted for this type of polymers with binders. This study aims to research the properties of glycoluril-formaldehyde additives in normal concrete and the effect of dosage levels on compressive strength, tensile strength, modulus of elasticity, and durability was studied. By this, the optimum dosage for polymer will be obtained.

\section{EXPERIMENTAL PROGRAM}

\subsection{Concrete mixes and casting}

The materials used to produce conventional and polymermodified concrete were 43 grade ordinary Portland cement conforming to IS8116 [21] with specific gravity 3.13, fineness $3 \%$ as per IS4031 [22], initial setting time of $164 \mathrm{~min}$, and final setting time of $283 \mathrm{~min}$. Zone 1 natural siliceous sand with 2.56 specific gravity and crushed stone from quarry as coarse aggregate having a specific gravity of 2.72 and maximum size of $20 \mathrm{~mm}$ [23]. As per the standard procedure stated by Ji-Tai Li [24] the glycoluril was synthesized. Formaldehyde was purchased in the local market. Table 1 shows the concrete mixture proportion and the mix was designed as per IS10262 [25]. These mix proportions are kept constant throughout the study. The concrete was modified using glycoluril by addition to the binder. The glycoluril-cement ratios applied in the study were $0 \%, 1 \%$, $2 \%, 3 \%$, and $4 \%$ by the mass of the binder.

At room temperature samples were prepared by mixing the required amount of glycoluril with cement in the dry 
Table 1. Concrete mix proportion

\begin{tabular}{lccccc}
\hline Nomenclature & Water $\left(\mathrm{kg} / \mathrm{m}^{3}\right)$ & Cement $\left(\mathrm{kg} / \mathrm{m}^{3}\right)$ & $\mathrm{FA}\left(\mathrm{kg} / \mathrm{m}^{3}\right)$ & $\mathrm{CA}\left(\mathrm{kg} / \mathrm{m}^{3}\right)$ & $\mathrm{Glycoluril}\left(\mathrm{kg} / \mathrm{m}^{3}\right)$ \\
\hline CS & 191.6 & 511 & 513 & 1,158 & 0 \\
GMC 1\% & 191.6 & 511 & 513 & 1,158 & 5.11 \\
GMC 2\% & 191.6 & 511 & 513 & 1,158 & 10.22 \\
GMC 3\% & 191.6 & 511 & 513 & 1,158 & 15.33 \\
GMC 4\% & 191.6 & 511 & 513 & 1,158 & 20.44 \\
\hline
\end{tabular}

state until uniform in appearance. After that, fine aggregate and coarse aggregate were added to the mix. The required amount of water was introduced and mixed thoroughly until the uniform mix was obtained. The interior surface of the steel moulds was thinly coated with mould oil and the prepared concrete mix was poured into the mould in layers with full compaction and ensured the symmetrical distribution of concrete in the mould.

\subsection{Curing}

The test specimens were kept at room temperature of 24 hours. Then the specimens were removed from moulds and immersed in $37 \%$ aqueous formaldehyde solution in an airtight container for 3 days, which allowed them to penetrate the specimen causing polymerization and then they were stored in clean water at a temperature of $25^{\circ} \mathrm{C} \pm 4{ }^{\circ} \mathrm{C}$ until the testing date.

\subsection{Experimental test}

2.3.1. Fresh properties of concrete mix. Fresh properties of the concrete mix were evaluated to determine the performance of the concrete mix [26]. For workability measure, slump cone and compaction factor tests were conducted in accordance with IS1199 [27].

2.3.2. Mechanical strength test. Mechanical strength according to IS516 [28] was conducted using L\&M CTM with accuracy of $2 \mathrm{kN}$ and FIE UTM with an accuracy of $1 \%$. $150 \mathrm{~mm}$ sized cube for compression, $150 \mathrm{~mm}$ diameter, $300 \mathrm{~mm}$ height cylinder was used to determine tension and modulus of elasticity and $100 \times 100 \times 500 \mathrm{~mm}$ prism for flexure. An average of three specimens were used. 7 days and 28 days aged specimens were tested. The load application was conducted continuously at a rate of $140 \mathrm{~kg} / \mathrm{cm}^{3}$ tile failure.

2.3.3. Water absorption test. The water absorption test was conducted after 28 days of the curing period and the specimen was prepared according to IS 1199 [27]. In this test, an average of three specimens was used for each nomenclature. After the water curing period specimens were oven-dried for $24 \mathrm{hrs}$ at $105^{\circ} \mathrm{C}$. Subsequently, the mass of all test specimens was measured for confirming the constant value and then immersed in water at $25^{\circ} \mathrm{C}-27^{\circ} \mathrm{C}$ for 24 hours. Then the surface of the specimens was wiped out and the mass of each was measured.
2.3.4. Sorptivity test. Sorptivity delivers a signal about the pore structure of the concrete and capillary. Low sorptivity means a dense concrete and ensures the higher resistance of aggressive ions into the concrete. After 28 days of curing the test specimens were oven-dried for 24 hours at $105{ }^{\circ} \mathrm{C}$ and the constant mass was ensured by weighing. Apart from the bottom surface, all sides of the specimens were coated by non-absorbent resin. Water was used as testing with $5 \mathrm{~mm}$ level. The test was carried out at 5, 10, 15, 20, 30 minutes intervals by measuring the mass of the specimen after wiping the surface.

2.3.5. Acid attack test. After 28 days of water curing the specimens were taken out and kept at room temperature for $24 \mathrm{hrs}$. Afterward, the specimens were weighed and their constant mass was confirmed. Then the specimens were immersed in 5\% sulfuric acid by the water mass for 60 days. After the desired period the specimens were taken out and washed with clear water and kept in room temperature for 24 hours for drying. Subsequently mass and compression tests were carried to calculate the percentage mass loss and strength loss.

\section{RESULT AND DISCUSSION}

\subsection{Fresh concrete test}

Slump clone test and compaction factor test were carried out to measure the workability of polymer modified concrete. The slump cone test result of all percentage variation in the polymer-modified concrete was $25^{\circ} \pm^{\circ} 3$ and the result of the compaction factor was $0.9^{\circ} \pm^{\circ} 0.6$. Results indicate that there is no noticeable change in the workability aspect of the modified concrete mix series from $0 \%$ to $4 \%$. This clearly shows that glycoluril addition will not affect the workability.

\subsection{Compression strength}

Figure 1 shows the compressive strength test of the cube in 7 days and 28 days of aging relations for conventional and glycoluril modified concrete. Compression strength was increased by polymeric dispersion caused by glycoluril of modified concrete. Early strength development in the 7 days tests was also noticeable by adding glycoluril showed in Fig. 2. This strength development can be explained by the polymeric process of modified concrete finished in the first 3 days while immersing test specimens in the formaldehyde. This polymeric reaction leads to filling the pores in concrete 


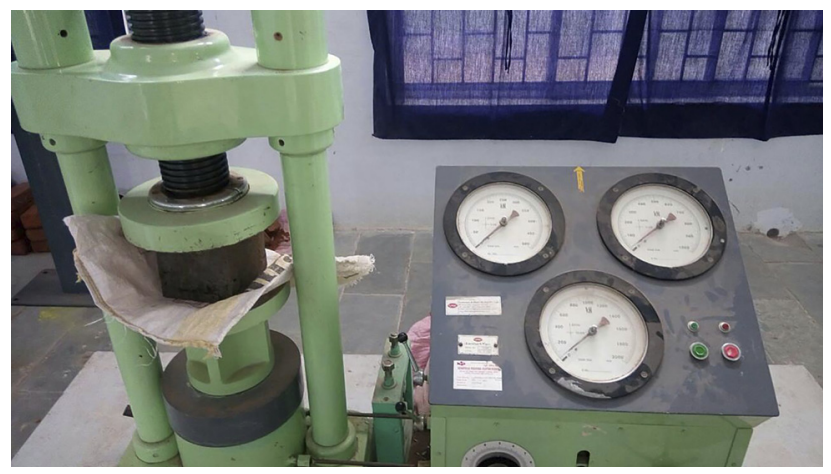

Fig. 1. Compression testing machine (CTM)

because the density of the concrete increased, and this behavior of polymer is responsible for increasing the strength. This is normal that the increase in strength is directly associated with a decrease in porosity. The incorporation of polymer tends to the gradual increase in strength up to $3 \%$ of addition and $4 \%$ is showing little less but the strength is more than the conventional concrete. This decreased strength is due to the excess amount of polymer in cement which may further affect the hydrates of the binder. This is also stated by Hongyan [7], Pascal [29], Ariffin [13], and Retno et al. [30].

\subsection{Split tensile strength}

The percentage of glycoluril addition was varied from $0 \%$ to $4 \%$ and the test was conducted after 28 days. Figure 3 exhibits the differing amount of glycoluril added in concrete and the effect of polymer on tension strength. Comparing the nominal concrete, the tensile strength of the concrete was improving by increasing the polymer content up to $3 \%$ as much as compressive strength. $3 \%$ addition of glycolurilformaldehyde gives the highest strength among all the content variations. The tensile strength was increased beyond $10 \%$ in a $3 \%$ addition of glycoluril. This is because of

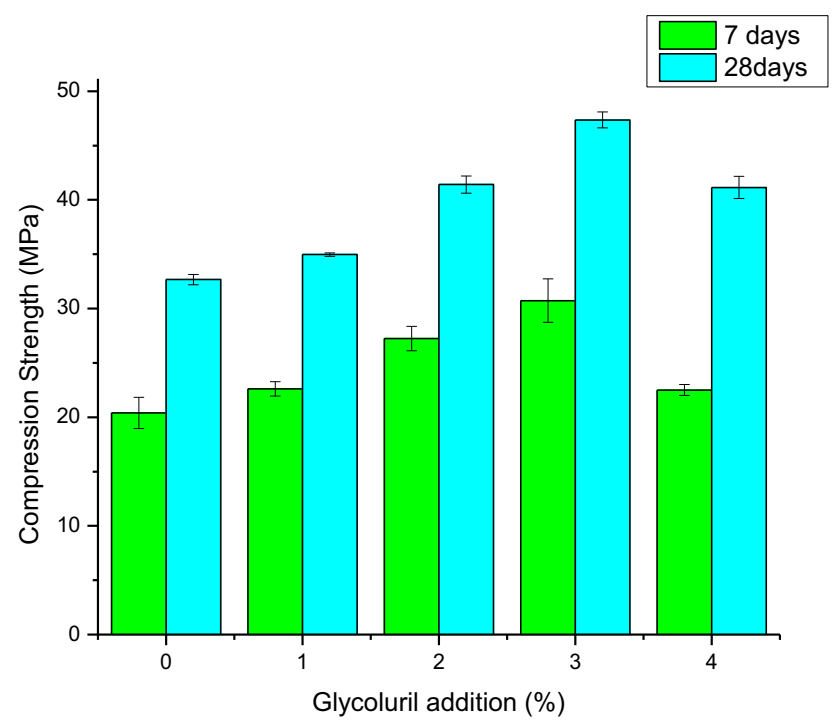

Fig. 2. Compression strength

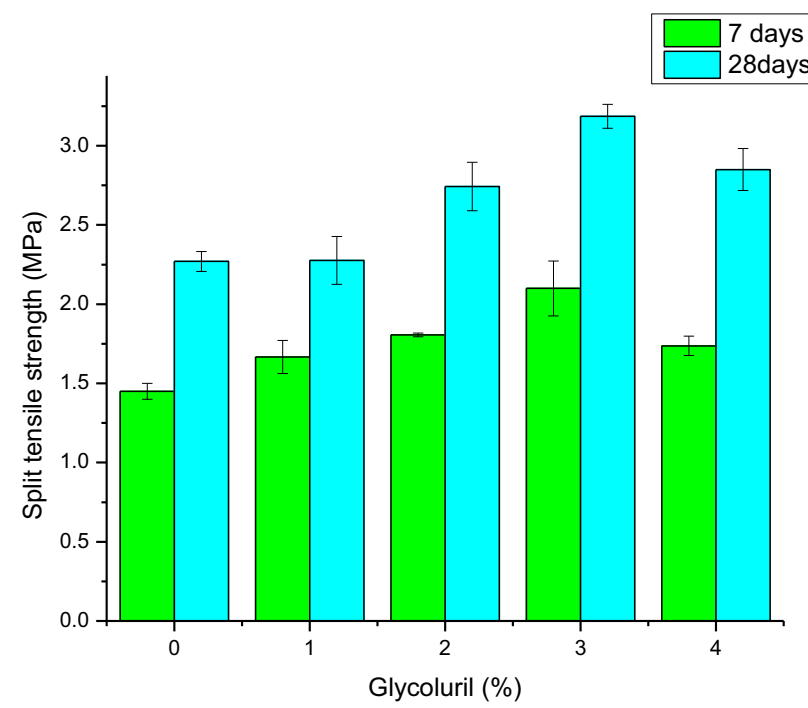

Fig. 3. Split tensile strength

the $\mathrm{NH}$ group in glycoluril, which provides good hydrogen bonding with cement.

\subsection{Flexure strength}

The ability of deformation of the materials was determined through the flexural test. 7 days test of $\mathrm{GMC} \%$ and GMC1\% was conducted. But the prism failed with null reading. So, the testing was stopped for further proportions. In this only 28 days test was carried out to determine the flexure strength of modified concrete. The result of the glycoluril modified concrete is shown in Fig. 3. In concrete with $3 \%$ glycoluril-formaldehyde, maximum flexural strength is revealed among other mechanical properties. Due to the polymerization, the concrete became denser and stronger. Again, the specimen is well qualified for the improvement in strength character.

\subsection{Water absorption test}

The water absorption test results of the specimen for 28 days of curing are shown in Fig. 4. This result indicates the rate of absorption of specimens was comparatively lower in polymer-modified concrete while comparing with normal concrete. It is clearly observed that water absorption decreases with increasing glycoluril. This is mainly due to the hydrogen bonding of glycoluril-formaldehyde with cement. That promotes fewer pores and dense concrete.

\subsection{Sorptivity test}

The capillary absorption is calculated by the square root of elapsed time. This test is commonly used to know the durability property by absorbing and transmit water. Fig. 5 . shows the result of average water sorption based on water capillary at 5, 10, 15, 20 and 30 min after 28 days of water curing. It absorbs that the mass of water capillary is decreased in increasing polymer content as indicated by the decreased slope of the curve in Fig. 5. It shows that the 


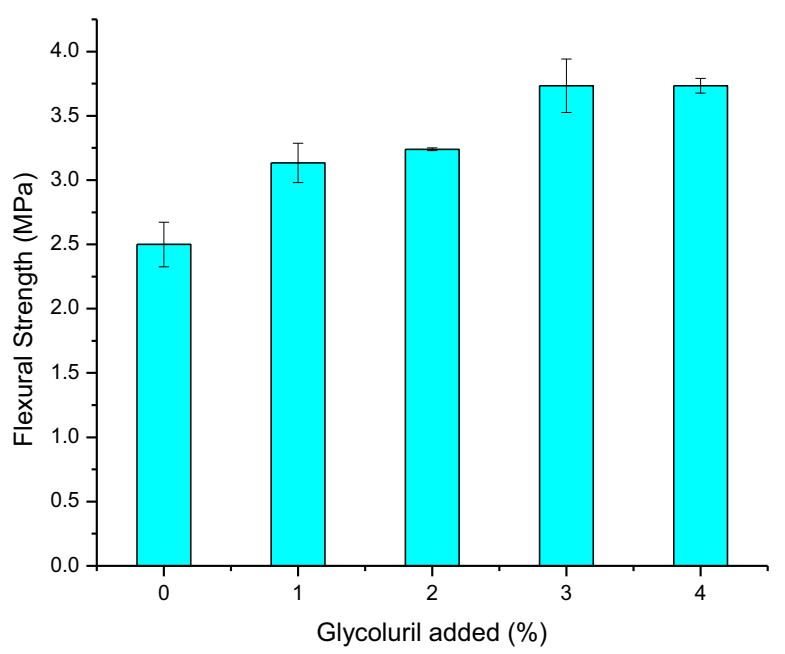

Fig. 4. Flexural strength

polymerization of glycoluril-formaldehyde contributes more to pores on the surface of the concrete. The incorporation of glycoluril-formaldehyde polymerization gives improved sorptivity resulting in the dense surface, which eliminated the capillary of chemicals inside the concrete.

\subsection{Acid attack test}

The resistance against sulphate attack on concrete was determined by loss of mass and compressive strength. In this, the specimens were immersed in $5 \%$ sulfuric acid by the water mass for 60 days. Figure 6 represents the percentage loss of mass and compressive strength due to acid attack. During this test no color change was noticed. The specimen remains grey in color after the soaking period. It indicates that the specimen suffered lightly in sulfuric acid. There are noticeable mass and strength losses in the concrete specimen. But as usual, 3\% addition of

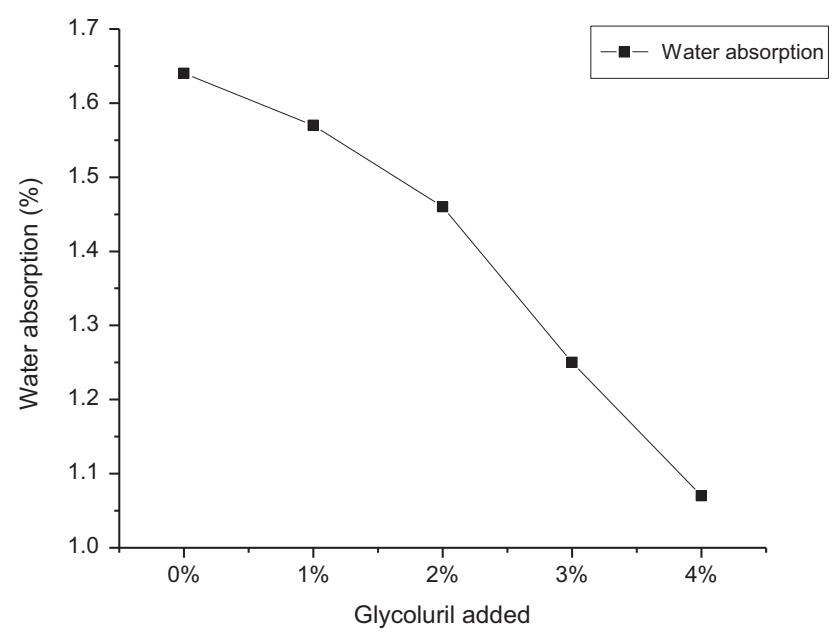

Fig. 5. Water absorption

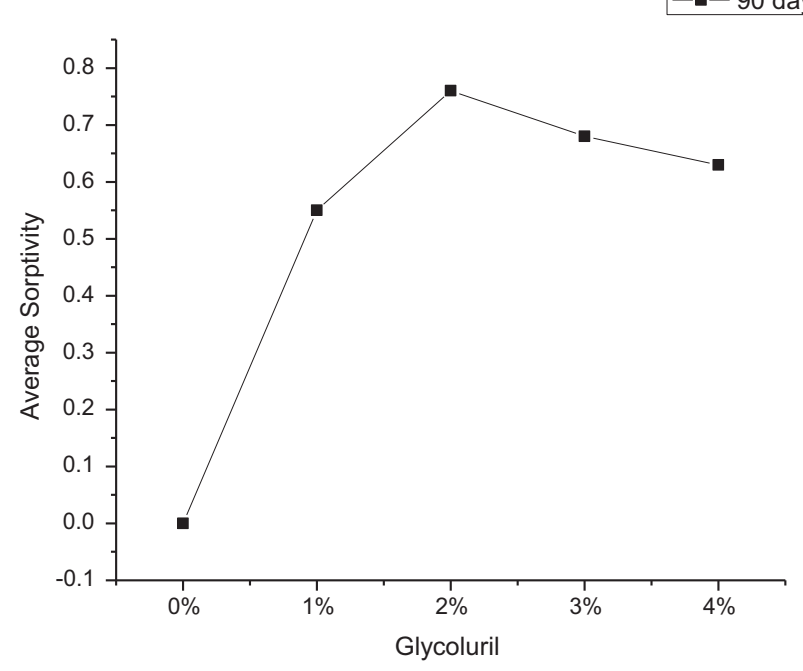

Fig. 6. Sorptivity test

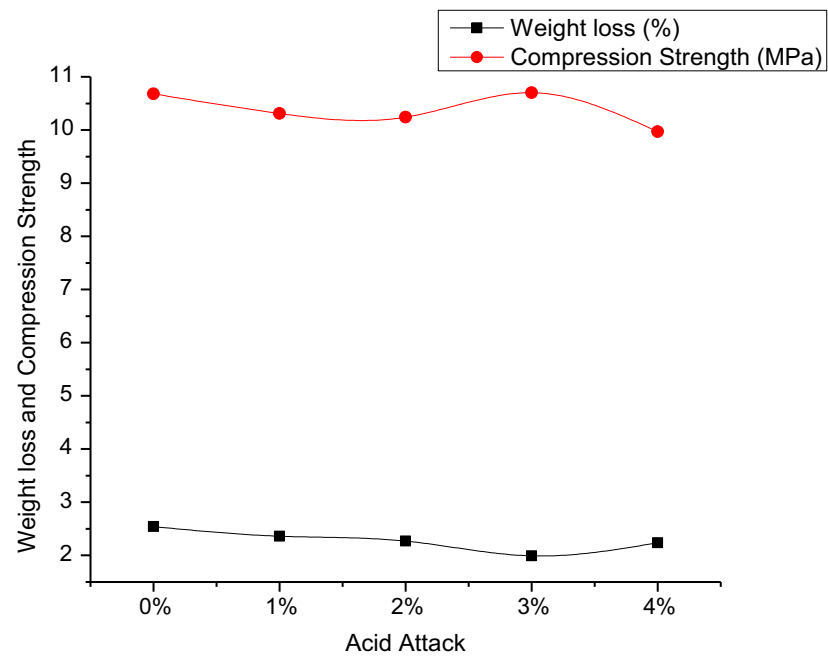

Fig. 7. Acid attack test

glycoluril shows little improved resistance against acid attack (Fig. 7).

\section{CONCLUSION}

The main objective of this study was to investigate the potential use of glycoluril-formaldehyde as a polymer in polymer-modified concrete. The followings are the conclusions drawn from the experimental investigation:

1. Results of slump cone and compaction factor test indicate that there is no noticeable change in the workability aspect on all modified concrete mix series.

2. The incorporation of polymer leads to gradual increase in strength. The amount of glycoluril content that gives 
maximum strength was $3 \%$. The results show a $28 \%$ hike in strength in both 7 days and 28 days tests.

3. The results of tension and flexure tests showed that the polymer plays a vital role in strength development. The highest tension and flexural strength development were $3 \%$, similarly to the compressive strength study.

4. The incorporation of glycoluril-formaldehyde polymerization gives improved sorptivity and absorption resisting property that results in the dense surface, which eliminated the capillary of chemicals inside the concrete.

5. There are noticeable mass and strength losses in the concrete specimen. But as usual, a 3\% addition of glycoluril shows little improved resistance against acid attack.

These results are auspicious for the use of glycolurilformaldehyde in concrete as polymer-modified concrete, especially where high mechanical strength and durability are required. The optimum level for good performance for both mechanical and durability property is $3 \%$.

Data availability statement: No data, models, or code were generated or used during the study.

\section{REFERENCES}

[1] P. A. M. Basheer, S. E. Chidiact, and A. E. Long, "Predictive models for deterioration of concrete," Construction Building Mater., vol. 10, no. 1, pp. 27-37, 1996.

[2] Y. Zhang, Y. Sun, K. Xu, Z. Yuan, J. Zhang, R. Chen, H. Xie, and R. Cheng, "Brucite modified epoxy mortar binders: flame retardancy, thermal and mechanical characterization," Construct. Building Mater., vol. 93, no. 15, pp. 1089-96, 2015.

[3] E. Abd, and M. Abd Elmoaty, "Self-healing of polymer modified concrete," Alexandria Eng. J., vol. 50, pp. 171-8, 2011. Available: https://doi.org/10.1016/j.aej.2011.03.002.

[4] A. Elbakyan, "Concrete," Building Mater. Civil Eng., pp. 81-423, 2001.

[5] Y. Ohama, Handbook of Polymer-Modified Concrete and Mortars Properties and Process Technology, Noyes Publications.

[6] Y. K. Jo, "Basic properties of epoxy cement mortars without hardener after outdoor exposure," Construct. Building Mater., vol. 22, pp. 911-20, 2008.

[7] H. Ma, and Z. Li, "Microstructures and mechanical properties of polymer modified mortars under distinct mechanisms," Construct. Building Mater., vol. 47, pp. 579-87, 2013.

[8] G. Barluenga, and F. Hernández-Olivares, "SBR latex modified mortar rheology and mechanical behavior," Cem. Concr. Res., vol. 34, pp. 527-35, 2004.

[9] B. Muhammad, and M. Ismail, "Performance of natural rubber latex modified concrete in acidic and sulfated environments," Construct. Building Mater., vol. 31, pp. 129-34, 2012.

[10] Z. Bahranifard, F. Farshchi Tabrizi, and A. Reza Vosoughi, "An investigation on the effect of styrene-butyl acrylate copolymer latex to improve the properties of polymer modified concrete," Construct. Building Mater., vol. 205, pp. 175-85, 2019.

[11] Y. Ohama, "Process technology of latex-modified systems," in Handbook of Polymer-Modified Concrete and Mortars, Elsevier, pp. 22-44, 1995.

[12] B. Łaźniewska-Piekarczyk, "Examining the possibility to estimate the influence of admixtures on pore structure of self-compacting concrete using the air void analyzer," Construct. Building Mater., vol. 41, pp. 374-87, 2013.

[13] N. Farhayu Ariffin, M. Warid Hussin, A. Rahman Mohd Sam, M. Aamer Rafique Bhutta, N. H. A. Khalid, and J. Mirza, "Strength properties and molecular composition of epoxymodified mortars," Construct. Building Mater., vol. 94, pp. 315-22, 2015.

[14] L. K. Aggarwal, P. C. Thapliyal, and S. R. Karade, "Properties of polymer-modified mortars using epoxy and acrylic emulsions," Construct. Building Mater., vol. 21, pp. 379-83, 2007.

[15] M. Shawqul, M. Lahallh, A. I.-Halabl, and A. M. All, "Effect of polymerization conditions of sulfonated-melamine formaldehyde superplasticizers on concrete," Cement Concrete Res., vol. 18, pp. 513-31, 1988.

[16] H. Duan, Z. Jiang, S. Zhu, P. Yao, and Q. Sun, "New composite grouting materials: modified urea-formaldehyde resin with cement," Int. J. Mining Sci. Technol., vol. 22, pp. 195-200, 2012.

[17] S. K. M. Pothinathan, M. Muthukannan, S. Narayanan, "Comparison of bond strength analysis on the interfacial layer of old and new concrete using latex, epoxy and glycoluril," IOP Conf. Ser. Mater. Sci. Eng., vol. 983, p. 012006, 2020. https://doi.org/10.1088/ 1757-899X/983/1/012006.

[18] V. R. Riley, and I. Razl, Polymer Additives for Cement Composites: Review, 1974.

[19] X.-M. Kong, C.-C. Wua, Y.-R. Zhang, and J.-L. Li, "Polymermodified mortar with a gradient polymer distribution: preparation, permeability, and mechanical behaviour," Construct. Building Mater., vol. 38, pp. 195-203, 2013. Available: https://doi.org/10. 1016/j.conbuildmat.2010.06.077.

[20] A. H. Gerber, and O. Solon, Additive for Hydraulic Cement, US Patent Aug 19, 1986.

[21] IS 8112, Ordinary Portland Cement, 43 Grade - Specification. New Delhi: Bureau of Indian Standards, 2013.

[22] IS4031, Methods of Physical Tests for Hydraulic Cement. New Delhi: Bureau of Indian Standards, 1996.

[23] IS 383, Specifications for Coarse and Fine Aggregates for Natural Sources of Concrete. New Delhi: Bureau of Indian Standards.

[24] J.-T. Li, X.-R. Liu, and M.-X. Sun, "Synthesis of glycoluril catalyzed by potassium hydroxide under ultrasound irradiation," Ultrason. Sonochem., vol. 17, pp. 55-7, 2010. Available: https://doi. org/10.1016/j.ultsonch.2009.04.010.

[25] IS 10262, Concrete Mix Proportioning - Guidelines. New Delhi: Bureau of Indian Standards, 2009.

[26] S. C. Gnanaraj and G. Ramesh Babu Chokkalingam, "Influence of ultra-fine steatite powder on the fresh and hardened properties of self-compacting concrete," in IOP Conference Series: Materials Science and Engineering, vol. 988, no. 1, p. 012040. IOP Publishing, 2020.

[27] IS1199, Methods of Sampling and Analyzing of Concrete. New Delhi: Bureau of Indian Standards, 1959. 
[28] IS516, Method of Tests for Strength of Concrete. New Delhi: Bureau of Indian Standards, 1959.

[29] S. Pascal, A. Alliche, and Ph. Pilvin, "Mechanical behaviour of polymer modified mortars," Mat. Sci. Eng. A-struct., vol. 380, pp. $1-8,2004$.
[30] R. M. I. Retno Susilorinia, H. Hardjasaputrab, S. Tudjonoc, G. Hapsaria, R. Wahyu Sa, G. Hadikusumoa, and J. Suciptoa, "The advantage of natural polymer modified mortar with seaweed: green construction material innovation for sustainable concrete," Proced. Eng., vol. 95, pp. 419-25, 2014. 